\title{
NIVEIS DE TREINAMENTO EM TERMOGRAFIA PARA PROFISSIONAIS DA SAÚDE
}

\author{
Marcos Leal Brioschi', Luciane Fachin Balbinot ${ }^{2}$, Carlos Dalmaso Neto ${ }^{3}$ \\ Presidente da Associação Brasileira de Termologia Médica (ABRATERM) \\ 2 Vice-presidente da Associação Brasileira de Termologia Médica (ABRATERM) \\ ${ }^{3}$ Médico. Pós-graduado em Dor pelo HIAE, Pós-graduado em Termologia e Termografia pela FMUSP, Mestrando em Engenharia \\ Mecânica pela UFPR
}

A ABRATERM, dentro de suas atribuições de ensino, pesquisa, capacitação e certificação de profissionais da área de saúde, organizou a classificação dos Cursos de Termologia e Termografia segundo níveis preconizados internacionalmente e critérios para o bom desempenho profissional e ético do termografista e do termologista perante seus pacientes, bem como os critérios para obtenção de certificação de membro titular ABRATERM.

CONHECIMENTO AVANCADO

APERFEICOOAMENTO \& NOVAS TÉCNICAS

EDUCAÇÄO CONTINUADA

DIAGNÓSTICO TERMOANATÔMICO, TERMOFISIOLÓgICO, TERMOMETABÓLICO CORPO TOTAL E SEGMENTAR

MONITORIZAÇĂO \& ACOMPANHAMENTO TÉRMICO PROCEDIMENTOS TERMOGUIADOS

CAPTURA DE IMAGENS DETECÇÃO DE ASSIMETRIAS 


\section{NÍVEL 1 - BÁSICO}

O curso de treinamento de Termografia Infravermelha Nível 1 é voltado para o novo usuário de aparelho infravermelho que quer aprender a capturar imagens térmicas e detectar assimetrias em diferentes situações clínicas cotidianas e em pesquisa. Os participantes que completarem todos os requisitos do curso de treinamento receberão uma Certificação ABRATERM em Termografia InfravermeIha Nível 1.

\section{OBJETIVOS DO NÍVEL 1}

- Introdução abrangente e prática a sistemas de imagens térmicas e de medição para aplicações na área de saúde. Não é necessária nenhuma experiência prévia em termografia!

- Aprender a capturar imagens térmicas e coletar dados de qualidade, fazer leituras precisas de temperatura, e saber levar em conta efeitos de medição como posicionamentos e emissividade usando aparelhos infravermelhos.

- Detectar e interpretar termogramas assimétricos e distinguir pontos quentes anormais para tomada de decisões usando conceitos de termobiologia para analisar imagens térmicas, por meio de termografia qualitativa e quantitativa. Ver o que há de mais recente em geração de relatórios de inspeção infravermelha e software de banco de dados.

- Evitar erros dispendiosos - aprender a indicar exame de termografia para diagnóstico, prevenção e monitoramento.

- Desafiar-se nas práticas de simulação de exames reais e uso de softwares que simulam avaliações cotidianas reais.

- Vale 2 pontos para Prova de Mem-

\section{bro Titular ABRATERM}

- Tópicos da formação do Termografista Nível 1:

1. Introdução

2. Visão geral das aplicações de termografia infravermelha

3. Configuração e Operação Básica dos Aparelhos

4. Princípios básicos da interface da câmera IR, descrição e navegação do menu, dicas e truques operacionais e elementos-chave para obter uma boa imagem infravermelha

5. Fundamentos da Ciência Térmica

6. Transferência de Calor

7. Fundamentos da Ciência do Infravermelho

8. Medições térmicas

9. Aplicações Médicas e da Área de Saúde

10. Revisão

11. Exame final ABRATERM

\section{NÍVEL 2 - MONITORAMENTO}

Cursos específicos por aplicação desenhados para profissionais de saúde termografistas praticantes que detenham o certificado de Nível 1, que queiram treinamento de infravermelho mais avançado para aumentar o seu conhecimento sobre a termografia infravermelha e que queiram se qualificar como Termografistas Certificados Nível 2 em aplicações específicas de monitoramento e/ou procedimentos termoguiados.

Este curso de treinamento em infravermelho se concentra no fortalecimento e aprimoramento das habilidades de termografia para monitoramento de condições e aplicações na avaliação preditiva/ 
preventiva e/ou procedimentos termo-

guiados. Os participantes que concluírem os requisitos do Curso de Infravermelho de Nível 2 receberão uma Certificação ABRATERM em Termografia InfravermeIha Nível $\mathbf{2}$ em aplicações específicas de monitoramento e/ou procedimentos termoguiados.

\section{ATRIBUIÇÕES DO NÍVEL 2}

Selecionar a técnica termográfica apropriada para monitoramento de condições clínicas e pesquisa e conhecer suas limitações. Aplicar a teoria termográfica incluindo medições e interpretação de resultados de monitoramento. Realizar processamento avançado de imagens e interpretação gráfica. Aplicar com qualidade procedimentos termoguiados. Orientar os profissionais de Nível I. Preparar relatórios sobre monitoramento de condição clínicas, ações corretivas e avaliação da efetividade de tratamentos e orientações preditivas.

\section{OBJETIVOS DO NÍVEL 2}

- Reforçar os conceitos do treinamento em infravermelho Nível I com material de reciclagem que abrange os mais recentes desenvolvimentos em aplicações do aparelho infravermeIho, tecnologia e geração de imagens térmicas.

- Evitar erros dispendiosos - os especialistas da ABRATERM analisam e explicam os equívocos e as más interpretações comuns da termografia por infravermelhos.

- Aprenda os fundamentos da termografia de avaliação preditiva/preventiva e do programa geral de monitorização por infravermelho.

- Aprimore a proficiência em análise e interpretação de imagens com um exame detalhado de imagens térmicas e técnicas de medição para aplicações mais específicas de mo- nitoramento preditivo como: inflamações articulares e periarticulares ou cardiovascular, neurológica, metabólica, miofasciais, ginecológico e mamas, postural, cerebral, visceral ou outros.

- Melhore suas habilidades de análise térmica com prática de laboratório para análise térmica mais específica e desafiadoras.

- Realizar com qualidade procedimentos termoguiados.

- Vale 4 pontos para Prova de Membro Titular ABRATERM

- Tópicos da Formação do Termografista Nível 2:

1. Introdução

2. Revisão da interface básica da câmera IR, descrição do menu e navegação, dicas e truques operacionais e elementos-chave para obter uma boa imagem de infravermelho

3. Teoria do Infravermelho / Radiosidade / Radiometria Aplicada

4. Princípios de transferência de calor

5. Resolução Espacial

6. Workshops de câmeras / exercícios de laboratório

7. Laboratório de software para análise de imagens e preparação de relatórios avançados de monitoramento

8. Visão Geral do Programa de Monitoramento da Condição Clínica como: inflamações articulares e periarticulares ou cardiovascular, neurológica, metabólica, miofasciais, ginecológico e mamas, postural, cerebral, visceral ou outros 
9. Resolver problemas do mundo real em condição de monitoramento

10. Procedimentos termoguiados

11. Aplicações em campo aberto

12. Apresentações de laboratório

13. Revisão

14. Exame final

15. Exame de Revisão

16. Requisitos de atribuição de campo

\section{NÍVEL 3 - ESPECIALIZAÇÃO}

O treinamento pleno de certificação nível $\mathbf{3}$ ensina de forma plena aos termologistas como estabelecer uma avaliação termográfica completa e integrativa de corpo total e segmentar bem-sucedidas, em uma variedade de aplicações médicas e da área de saúde e pesquisa biológica. O conteúdo inclui instruções amplas sobre como estabelecer procedimentos de avaliação termográfica, aplicar padrões específicos de análise para diferentes especialidades médicas e da saúde, utilizar todos os recursos de equipamentos e softwares, e implementar protocolos de tratamentos termoguiados. Ampliar os conhecimentos e conteúdo do Nível $\mathbf{1}$ e $\mathbf{2}$ na forma de programa de Pós-Graduação/Especialização certificado pelo MEC.

Os participantes também aprendem como desenvolver uma lista mais ampla de hipóteses diagnósticas, estabelecer critérios de gravidade, definir prioridades de tratamento e determinar frequências de reavaliação infravermelha; todos os elementos críticos de um programa de rastreamento e diagnóstico bem-sucedido. Também é enfatizado o trabalho prático com laboratórios que reforçam os princípios discutidos, incluindo exercícios que abordam a ciência biotérmica avançada, procedimentos diagnósticos e termoguia- dos preconizados pela literatura científica e padrões da área de médica. Realização de trabalho de conclusão de curso.

\section{OBJETIVOS DO NÍVEL 3}

- Identificar os requisitos de segurança para termógrafos e pessoal de acompanhamento para pesquisas em infravermelho.

- Reconhecendo os principais elementos de um programa bem-sucedido de Termografia por infravermelho.

- Compreender o processo usado para criar um procedimento infravermeIho.

- Aprender como criar um orçamento de termografia por infravermelho.

- Desenvolver uma prática escrita para os termógrafos de Nível 1, Nível 2 e Nível 3.

- Criando um modelo de relatório de imagem infravermelha personalizado e procedimentos de relatório adequados.

- Se preparar para prova de membro titular ABRATERM.

- Preparar para treinamento de termografistas Nível 1 e 2.

- Vale 10 pontos para Prova de Membro Titular ABRATERM

- Tópicos da Formação do Termografista Nível 3:

1. Especialização em Termologia e Termografia Médica Aplicada

2. Especialização em Termologia e Termografia do Movimento e Esporte (Multidisciplinar)

3. Especialização em Termologia e Termografia Craniocervical (Multidisciplinar) 


\section{NÍVEL 4 - AVANÇADO}

Cursos específicos por aplicação desenhados para profissionais de saúde termologistas formados, praticantes, obrigatoriamente detentores do Certificado Nível 3, que queiram educação continuada e treinamento de infravermelho mais avançado para aumentar o seu conhecimento sobre a termografia infravermelha com as novidades e descobertas mais recentes. Cursos atuais e de reciclagem de diagnóstico, monitoramento e procedimentos termoguiados.

\section{OBJETIVOS DO NÍVEL 4}

- Aperfeiçoamento

- Aprender novas técnicas

- Qualificação como termologistas certificados Nível 4

- Preparação para treinamento de Termografistas Níveis 1, 2 e 3

- Vale 10 pontos (4 módulos) para Prova de Membro Titular ABRATERM

- Tópicos da Formação do Termografista nível 4:

1. Encontro Avançado de Termologia 